\title{
Research on Intelligent Evaluation System of Load-bearing Capacity of Existing Reinforced Concrete Bridge
}

\author{
An Zhao $^{1 *}$, Qiang $\mathrm{Xu}^{2}$ and Jianyong Song ${ }^{3}$ \\ ${ }^{1}$ Research Institute of Highway Ministry of Transport, BeiJing, 100088, China
}

\begin{abstract}
The intelligent evaluation system of existing reinforced concrete bridge "BLP" is a special software for the load-bearing capacity rapid analysis and evaluation of the existing reinforced concrete bridge, which was developed by the Highway Research Institute of the Ministry of Transport. Based on the parametric modelling method, it can quickly and easily establish the finite element plane model of the bridge structure for the static analysis of ultimate bearing capacity limit states and serviceability limit state, under variety norms. And it can easily and quickly build variable-section beams and rebars, with the special module. According to the comprehensive modification method of the load-bearing capacity evaluation, it can automatically recommend checking sections, and automatically calculate partial modification coefficient of resistance effect, and conveniently judge the safety coefficient of the sections, and quickly get the results of bridge load-bearing capacity. In summary, this system can significantly improve the work efficiency and accuracy of load-bearing capacity for exiting reinforced concrete bridge. This paper introduces in detail the characteristics of the intelligent analysis technology, calculation principle and real bridge application examples of the system.
\end{abstract}

\section{Introduction}

In general, the existing bridges in one of the following situations [1], the load-bearing capacity should be inspected and evaluated: 1) Bridges with technical conditions of grades 4 and 5; 2). Bridges intended to increase the load level; 3 ). Bridges that need to be loaded by special heavy vehicles; 4) Bridges that have suffered major natural disasters or accidents.

In the past, people often relied on load test methods to evaluate the load-bearing capacity. Although the accuracy of the results of this method is relatively high, the cost is relatively high, which is not suitable for large-scale and regular assessment of the carrying capacity of bridges.

This software was based on the comprehensive modification method of the load-bearing capacity evaluation for the existing reinforced concrete bridge. Assessing the bearing capacity of a bridge, this method is practical, economical, reasonable, and reliable, which has changed the situation that the evaluation of the loasbearing capacity of highway bridges relied too much on load test identification, and can generally saves $50 \%$ to $60 \%$ of the funds for the load-bearing capacity of the bridge[2].

The operation of this software mainly includes four steps: 1) Establishing finite element models (including steel bars), 2) Calculating resistance reduction coefficients based on bridge defects, materials, and state parameters, 3) Calculating load effects and resistance effects based on current load conditions and design loads, 4) Automatically comparing the load effect and the resistance effect after modification to judge the load-bearing capacity.

\section{The problems of past common software in load-bearing capacity analysis}

Most of the conventional bridge load-bearing capacity calculation methods use manual or semi-manual algorithms $[3,4]$. The calculation process is tedious, and it depends too much on human factors. After inspecting the bridge's various performance indicators, the bridge inspectors need to process a large amount of inspection data, and spend a lot of time to organize the data by different office software, calculating the partial modification coefficients by manual.

When calculating structural resistance and load effects [5], the bridge inspectors usually used large-scale finite element software such as ANSYS, Midas, and Dr. Bridge, which exist the following problems:

ANSYS software is a general-purpose large-scale finite element program with abundant types and powerful calculation functions. But it's specificity of bridge is poor, and the modelling is cumbersome, and the highway design load simulation is difficult, and the post-processing workload is huge.

The other software, such as MIDAS / Civil and Dr. Bridge are professional software for bridge structure design, which pay much attention to the development of design calculation and drawing functions. There are many calculation and construction stages and comprehensive calculation content. For the analysis of bridge structure

*An Zhao: 279101052@QQ.com 
load-bearing capacity, unnecessary information such as the construction stage needs to be entered. They are unable to quickly and automatically obtain the internal force value results of key sections of the bridge structure.

In conclusion, in the assessment of the load-bearing capacity of the bridge structure, the other softwires are low degree of automation and low work efficiency.

\section{Analytical techniques for load-bearing capacity evaluation}

\subsection{The framework of BLP software}

In order to solve the above problems, this paper proposes to establish an automated and integrated load-bearing capacity rapid evaluation system for reinforced concrete bridges under operation status, establishing a dedicated load capacity analysis and comparison module.

This system framework consists of three parts: modeling, calculation of partial modification coefficients, and evaluation of load-bearing capacity. The modeling module can establish plane linkage model of multiple bridge structures including equal-section beams, variablesection beams, and multi-slice beams; The calculation module of partial modification coefficients is based on the results of inspection and assessment of bridge defects, and material and state parameter data. The partial modification coefficients are calculated automatically in accordance with the "Specification for Inspection and Evaluation of Load-bearing Capacity of Highway Bridges " (JTG / T J21-2011). The operating status load-bearing capacity evaluation module can automatically recommend the check sections, and respectively carry out the limit state of load-bearing capacity under 85,04 , and 18 specifications, automatically determine the bridge load capacity results, through the load capacity analysis and comparison module.

\subsection{Rapid modeling technology}

In order to make the modeling process intuitive and convenient, basing on the parametric modelling ideas and according to the location and function of the bridge structure, the system divides the bridge structure into bridge deck elements, non-bridge deck elements, and support bar elements, as shown in fig 1. Deck elements refer to the main load-bearing upper structural part of where the bridge is in contact with the wheels; Non-deck elements refer to the structural part such as bridge piers, towers, arches that do not contact the wheels; Support bar elements are used to simulate the structural support boundary condition.

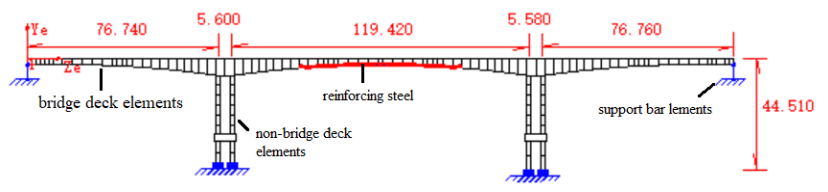

Fig. 1 Plane model structure Figure

According to the characteristics of different element groups, the data input interfaces are designed to input, check and modify the information required for finite element calculations such as element coordinates, structural materials, and geometry section. The coordinate information of the bridge deck element is described by the node number, the element length, and the starting station number. The system can calculate the coordinates of each element node based on the information of the horizontal curve and vertical curve of the route. The constraints of the bridge support are given in four directions: horizontal, vertical, corner, and lateral. The position of the constraint is described by the station number of the constraint point and the distance from the bridge deck.

In the form of bridge structure, variable cross-section bridge is a very common form, and its cross-section changes along the bridge deck axis. If the general method is used for the modeling, a large number of sections will be input, the work efficiency is low, and the accuracy is difficult to guarantee. Bridges, arch bridges, arches, and substructures are re-divided to automatically generate data on internally-differenced elements.

The system establishes the internal difference function of the elements by lagrangian difference method, which can easily re-divide the element of equal-section or variable-section beam bridges, arch bridges, and substructures, and automatically generate relevant data of internal difference elements.

For reinforced concrete bridges, reinforcing steel is an important structure. According to the habits of engineers, this system provides a simplified and fast reinforcement input module, the result is as shown in Figure 2. The section parameters of the reinforcement are divided into group information and reinforcement wire point information. Rebars with the same lateral spacing, vertical spacing, mechanical parameters and other parameters are defined as a group, and the reinforcement wire information describes the complex curve geometric information of the reinforcement by the coordinate information of several simplified key points.

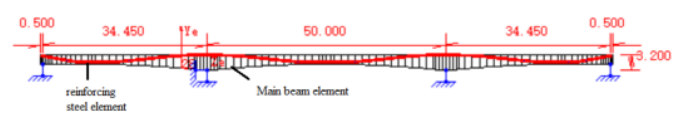

(a) Modal with steel

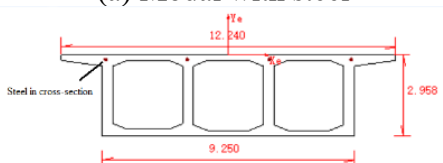

(b) steel in cross-section

Fig. 2 Reinforced concrete bridges model

\subsection{Calculation of partial modification coefficients}

The calculation of partial modification coefficients is the most important work for the evaluation of the load-bearing capacity of bridges. The partial modification coefficients mainly include: the comprehensive modification coefficient $\mathrm{Z} 1$ or $\mathrm{Z} 2$ that reflects the overall technical condition of the bridge; Section reduction factors $\xi_{c}$ and $\xi_{s}$, considering effective section reduction of the structure; 
deterioration coefficient of load-bearing capacity $\xi_{e}$ that takes into account the effects of structural durability; and live-load modified coefficient $\xi_{q}$ that reflects the actual traffic load variation.

For masonry and reinforced concrete bridges, this system has established detection parameter input interfaces for each sub-item partial modification coefficient.

Accordance to the correlation coefficient determination tables in the " Specification for Inspection and Evaluation of Load-bearing Capacity of Highway Bridges" (JTG / T J21-2011), and the partial coefficient scale calculation formula (1), this system can automatically calculate the partial modification coefficients, and reduce manual calculation errors, providing work efficiency.

$$
E=\sum_{j=1}^{n} E_{j} a_{j}
$$

E- Partial coefficient scale; $E_{j}$ - Scale of an inspection and evaluation index of a structure or component; $a_{j}$ - The weight of an inspection and evaluation index.

\subsection{Evaluation of load-bearing capacity in operational state}

Based on the established finite element model, this system automatically recommends check sections and separately carry out limit state verification of bearing capacity and normal test limit state for masonry and reinforced concrete bridges in accordance with the provisions of "Specification for Inspection and Evaluation of Loadbearing Capacity of Highway Bridges" (JTG / T J212011).

According to formula (2), it carries out limit state strength check calculation of load-bearing capacity of critical section. According to the formulas $(3,4,5)$, it performs normal test limit state check calculation of stress, deformation, crack width of the key section position.

$$
\gamma_{0} S \leq R\left(f_{d}, \xi_{c} a_{d c}, \xi_{s} a_{d s}\right) Z_{1}\left(1-\xi_{e}\right)
$$

$\gamma_{0}$ - Structure importance factor; $S$ - Load effect function; $R$ - Resistance effect function; $f_{d}$ - Design value of material strength; $\xi_{c}$ - Cross-section reduction factor for reinforced concrete structures; $a_{d c}$ - Component concrete geometric parameter values; $\xi_{s}$ - Reinforcement section reduction factor; $a_{d s}$-Rebar geometric parameter values; $Z_{1}$-Modification coefficient of load-bearing Capacity.

$$
\sigma_{d}<Z_{1} \sigma_{L}
$$

$\sigma_{d}$ - Section stress including live load correction factor; $\sigma_{L^{-}}$Stress limit.

$$
f_{d 1}<Z_{1} f_{L}
$$

$f_{d 1}$ - Load deformation including live load correction factor; $f_{L}$-Deformation limit.

$$
\delta_{d}<Z_{1} \delta_{L}
$$

$\delta_{d}$ - Short-term load deformation including live load correction factor; $\delta_{L}$-Displacement limit.

\section{Application examples}

A pedestrian bridge across highway, with a total length of $43.0 \mathrm{~m}$, span combination of $2 \times 21.5 \mathrm{~m}$, and the structural form is a reinforced concrete continuous box girder. The box girder beam is $1.15 \mathrm{~m}$ high, and the top width is $4.0 \mathrm{~m}$, and the bottom width is $1.8 \mathrm{~m}$. The beam is made of $\mathrm{C} 30$ concrete, and the design crowd load is $3.5 \mathrm{kN} / \mathrm{m}^{2}$, and the second stage dead load is $6.44 \mathrm{kN} / \mathrm{m}$, hot-rolled HRB335II grade steel. The partial modification coefficients are calculated as follows:

\section{1 comprehensive modification coefficient $\mathrm{Z1}$}

According to the "Standards for Technical Condition Evaluation of Highway Bridges" (JTG / T H21-2011), the bridge's technical condition rating is rated as Class 2 . The bridge is slightly defective, and it has no effect on the use of the bridge. Defect status rating scale is 2 .

The strength of the bridge body was tested. The average converted strength value of the concrete measuring area of the beam body Rim is $35.6 \mathrm{MPa}$, and the estimated value of the beam body strength Rit is $34.0 \mathrm{MPa}$. The design value of the beam strength $\mathrm{R}$ is $30.0 \mathrm{MPa}$. So, $\mathrm{Kit}$ is 1.13 ; and $\mathrm{Kbm}$ is 1.18 The strength of the beam body is good, and the material strength evaluation scale is 1 .

Without any external load on the bridge deck, the measured natural frequency fmi is $5.53 \mathrm{~Hz}$, and the theoretically calculated natural frequency fdi is $5.01 \mathrm{~Hz}$. So, fmi / fdi is 1.10, the scale of natural frequency evaluation is 2 .

The rating scale of the comprehensive modification coefficient is 1.7 , and the comprehensive modification coefficient of load-bearing capacity Z1 is 1.115 .

\section{2 deterioration coefficient of load-bearing capacity $\xi_{e}$}

The corrosion potential level of the steel bar in the main stress part of the beam is $\geq-200 \mathrm{mV}$, and the scale of the steel rod corrosion potential is 1 .

The resistivity of concrete is $\geq 20000 \Omega$.cm, and the possible corrosion rate of the steel bar is very slow, so, the scale of the concrete resistivity evaluation is 1 . The average thickness of the steel bar protection layer $D_{n}$ is $32.13 \mathrm{~mm}$, and the standard deviation $\mathrm{S}_{\mathrm{n}}$ is 2.79 , and the characteristic value $D_{n e}$ is 26.75 . Design value $D_{n d}$ is $36 \mathrm{~mm}$, So, $D_{n e} / D_{\text {nd }}$ is 0.74 . The thickness of the protective layer of the reinforcement has an influence on the durability, and the evaluation scale is 3 .

The carbonization depth of the concrete was measured in the rebound test area of the beam body. The average carbonization depth of the concrete is $5.0 \mathrm{~mm}$, So, $\mathrm{Kc}$ is 0.15 , and the evaluation scale is 1 .

The chloride content of concrete in the main stress part of the beam is less than 0.15 , and the evaluation scale is 1 .

The bridge is located in a dry, non-freezing, nonerosive environment, and the deterioration condition evaluation scale $\mathrm{E}$ is 1.56 , and the deterioration coefficient $\xi_{e}$ is 0.0112 .

\subsection{Section reduction factor $\xi_{c}$ and $\xi_{s}$}

After inspection, the weathering evaluation scale of the bridge material is 1 . The surface area of the component is 
within 5\%, so, the physical and chemical damage assessment scale is 1 .

The comprehensive damage assessment scale is 1.0, and the section reduction coefficient $\xi_{c}$ is $0.98 \sim 1.00$.

The bridge surface cracks along the steel bars, and the width is less than the limit, so, the reduction coefficient of the steel bar section $\xi_{s}$ is $0.98 \sim 1.00$.

\subsection{Load-carrying capacity evaluation}

Based on the aforementioned partial modification coefficients, under the design specifications of the bridge, the load-bearing capacity of the key sections was evaluated. The results are as follows:

Table 1 The results of load-bearing capacity

\begin{tabular}{|c|c|c|c|c|}
\hline \multicolumn{2}{|c|}{ Check Program } & $\begin{array}{l}\text { Load } \\
\text { effect }\end{array}$ & $\begin{array}{c}\text { Design } \\
\text { resistance } \\
\text { effect }\end{array}$ & $\begin{array}{c}\text { Real } \\
\text { resistance } \\
\text { effect }\end{array}$ \\
\hline \multirow{3}{*}{$\begin{array}{l}\text { Bending } \\
\text { strength }\end{array}$} & $\begin{array}{c}\text { Max- } \\
\text { positive }\end{array}$ & $\begin{array}{l}2043.52 \\
(\mathrm{kN} . \mathrm{m})\end{array}$ & $\begin{array}{c}2295.86 \\
(\mathrm{kN} . \mathrm{m})\end{array}$ & $\begin{array}{c}2531.21 \\
\text { (kN.m) }\end{array}$ \\
\hline & $\begin{array}{c}\text { Max- } \\
\text { negative }\end{array}$ & $\begin{array}{c}-3234.14 \\
(\mathrm{kN} . \mathrm{m})\end{array}$ & $\begin{array}{l}3986.40 \\
\text { (kN.m) }\end{array}$ & $\begin{array}{l}4395.06 \\
(\mathrm{kN} . \mathrm{m})\end{array}$ \\
\hline & & $\begin{array}{l}\text { theoretica } \\
\text { I value }\end{array}$ & $\begin{array}{c}\text { Actual } \\
\text { calculated } \\
\text { value }\end{array}$ & $\begin{array}{c}\text { allowable } \\
\text { value }\end{array}$ \\
\hline \multirow{2}{*}{$\begin{array}{l}\text { Crack } \\
\text { width }\end{array}$} & $\begin{array}{c}\text { Max- } \\
\text { positive } \\
\text { bending } \\
\text { moment }\end{array}$ & $\begin{array}{l}0.16 \\
(\mathrm{~mm})\end{array}$ & $0.16(\mathrm{~mm})$ & $\begin{array}{c}0.20 \\
(\mathrm{~mm})\end{array}$ \\
\hline & $\begin{array}{c}\text { Max- } \\
\text { negative } \\
\text { bending } \\
\text { moment }\end{array}$ & $\begin{array}{c}0.12 \\
(\mathrm{~mm})\end{array}$ & $0.12(\mathrm{~mm})$ & $\begin{array}{c}0.20 \\
(\mathrm{~mm})\end{array}$ \\
\hline $\begin{array}{c}\text { Deforma } \\
\text { tion }\end{array}$ & $\begin{array}{c}\text { Max- } \\
\text { positive } \\
\text { bending } \\
\text { moment }\end{array}$ & $\begin{array}{l}13.64 \\
(\mathrm{~mm})\end{array}$ & $\begin{array}{l}13.05 \\
(\mathrm{~mm})\end{array}$ & $\begin{array}{l}36.00 \\
(\mathrm{~mm})\end{array}$ \\
\hline
\end{tabular}

Since the calculated value of the modification coefficient $\mathrm{Z} 1$ is 1.115 greater than 1 , the section reduction factor $\xi_{c}$, the steel section reduction factor $\xi_{e}$, and the deterioration factor $\xi$ e are all smaller, so the bending strength resistance of the normal section of the structure is greater than the original design resistance, and the deformation of structure under the load is reduced, and the current load-bearing capacity of the bridge meets the traffic requirements under the design code.

\section{Conclusion}

